\title{
Determination of Oxygen Nonstoichiometry and Diffusivity in Mixed Conducting Oxides by Oxygen Coulometric Titration
}

\author{
II. Oxygen Nonstoichiometry and Defect Model for $\mathrm{La}_{0.8} \mathrm{Sr}_{0.2} \mathrm{CoO}_{3-\delta}$
}

\author{
M. H. R. Lankhorst and H. J. M. Bouwmeester \\ Laboratory for Inorganic Materials Science, Department of Chemical Technology, University of Twente, \\ 7500 AE Enschede, The Netherlands
}

\begin{abstract}
The oxygen nonstoichiometry of $\mathrm{La}_{0.8} \mathrm{Sr}_{0.2} \mathrm{CoO}_{3-\delta}$ has been determined as a function of oxygen partial pressure and temperature using a high-temperature coulometric titration cell. For each measured value of the oxygen chemical potential, the oxygen nonstoichiometry is found to be nearly independent of temperature. The equilibrium partial energy and entropy associated with oxygen incorporation have been determined as a function of oxygen nonstoichiometry and temperature. The results are interpreted in terms of a model in which it is assumed that conduction electrons, created during vacancy formation, gradually fill electron states in a wide electron band. A new relation between vacancy concentration, temperature, and oxygen partial pressure has been formulated which does not have the familiar appearance of a mass action type of equation.
\end{abstract}

\section{Introduction}

Acceptor-doped cobaltite perovskite-type oxides are characterized by enhanced lattice oxygen vacancy formation, which results in substantial departures from oxygen stoichiometry at increased temperatures. A change in the vacancy concentration is accompanied by a corresponding change in the average valence of either the cobalt or oxygen ions. The high concentration of oxygen vacancies in conjunction with their relatively high mobility cause these materials to exhibit high oxygen ion conductivity. The electronic conductivity is even higher and becomes metallic at high temperatures. Due to the mixed conductivity, these materials are permeable to oxygen gas. Advantageous use can be made as a ceramic membrane for the separation of oxygen from air, e.g., for the production of oxygen and nitrogen or for selectively feeding of oxygen into chemical reactors.

The defect equilibria for the formation and annihilation of ionic and electronic defects by the reaction of the oxide with the gas phase are commonly analyzed using a traditional formalism ${ }^{1,2}$ in which the relationships among defect concentrations and environmental parameters can be expressed by simple mass action type of equations. The latter are based on the assumption that all involved point defects can be treated as noninteracting and ideally diluted species for which corresponding chemical potentials can be defined. Such a formalism has been applied successfully to model experimental data of oxygen nonstoichiometry and electrical conductivity of $\mathrm{La}_{1-x} \mathrm{Sr}_{x} \mathrm{FeO}_{3-\delta}$ and $\mathrm{La}_{1-x} \mathrm{Sr}_{x} \mathrm{CrO}_{3-\delta}{ }^{3}$ In these compounds the transition metal ions are assumed to be charge disproportionated among three different valence states. Electronic charge carriers introduced either by acceptor doping or by oxygen vacancy formation upon decreasing the oxygen partial pressure occupy localized transition-metal $3 \mathrm{~d}$ states. The validity of the charge disproportionation model cannot be assumed a priori for compounds $\mathrm{La}_{1-x} \mathrm{Sr}_{x} \mathrm{CoO}_{3-\hat{\imath}}$. There is substantial evidence for itinerant electron behavior in these compounds. Using UPS and Bremsstrahlung isochromat spectroscopy, Sarma et al. ${ }^{4}$ observed significant spectral intensities at the Fermi energy. They concluded that electron hole states, created by substitution of La by Sr, overlap the top of the wide oxygen $2 p$ band giving rise to a mixed-valence metallic compound. The relatively large electronic conductivity and low Seebeck coefficients observed for the lanthanum-based cobaltite perovskites $^{5,6}$ also favor the interpretation in terms of itinerant electrons.

The general aim of this paper is to obtain insight in the thermodynamics of oxygen incorporation into perovskites
$\mathrm{La}_{1-x} \mathrm{Sr}_{x} \mathrm{CoO}_{3-\delta}$. Data of oxygen nonstoichiometry and partial energy and entropy of oxygen are measured for the compound $\mathrm{La}_{0.8} \mathrm{Sr}_{0.2} \mathrm{CoO}_{3-\delta}$ using high temperature oxygen coulometric titration. Data of chemical diffusion coefficient for $\mathrm{La}_{0.8} \mathrm{Sr}_{0.2} \mathrm{CoO}_{3-\delta}$ obtained with this technique have been presented in Part I of this paper.?

\section{Theory}

Oxygen coulometric titration.-In a high-temperature oxygen coulometric titration experiment the oxide sample is enclosed in a sealed electrochemical cell. The oxygen stoichiometry of the sample is adjusted by electrochemically pumping oxygen into or out of the cell using a solid electrolyte. The oxygen chemical potential of the sample inside the sealed compartment $\mu_{\mathrm{O}_{2}}^{\text {oxide }}$ is determined from the $E M F$ measured across an auxiliary electrolyte using identical metallic probes

$$
E M F=\frac{\mu_{O_{2}}^{\text {ref. }}-\mu_{\mathrm{O}_{2}}^{\text {oxide }}}{4 F}
$$

where $F$ is Faraday's constant and $\mu_{\mathrm{O}_{2}}^{\text {ref. }}$ the oxygen chemical potential of the reference gas (e.g., air), the value of which can be calculated by substituting the values of the oxygen partial pressure and temperature into Eq. A-1 given in the Appendix. When the above procedure to determine $\mu_{\mathrm{O}_{2}}^{\text {oxide }}$ is performed as a function of temperature at constant oxygen stoichiometry of the sample, the entropy part of $\mu_{\mathrm{O}_{2}}^{\text {oxide }}, s_{\mathrm{O}_{2}}^{\text {oxide }}$ defined by

$$
s_{\mathrm{O}_{2}}^{\text {oxide }}=-\left(\frac{\partial \mu_{\mathrm{O}_{2}}^{\text {oxide }}}{\partial T}\right)_{\delta}
$$

may be evaluated. The energy part $\epsilon_{\mathrm{O}_{2}}^{\text {oxide }}$ may be calculated from $\mu_{\mathrm{O}_{2}}^{\text {oxide }}=\epsilon_{\mathrm{O}_{2}}^{\text {oxide }}-T s_{\mathrm{O}_{2}}^{\text {oxide }}$.

As was discussed in Part $\mathrm{I}^{7}{ }^{7}$ electrochemical pumping of oxygen is generally performed using either galvanostatic or potentiostatic methods. Both methods allow evaluation of the change in oxygen nonstoichiometry of the sample $\Delta \delta$ by integration of the current $I$ over time

$$
\Delta \delta=\frac{m_{\text {molar mass }}}{m_{\text {sample }}} \int_{t=0}^{t=\infty} \frac{I(t)-I_{\text {leak }}}{2 F} d t
$$

where $I_{\text {leak }}$ is the unavoidable leakage current, $m_{\text {sample }}$ the mass of the sample, and $m_{\text {molar mass }}$ the molar mass. The potentiostatic method allows easy determination of $I_{\text {leak }}$ by measuring the value to which the current decays after a potentiostatic step. In the galvananostatic method, $I_{\text {leak }}$ can 
be calculated from the change in $E M F$ with time when the sample is in equilibrium with the surrounding gas.

Nonstoichiometry models: charge disproportionation model.-Mizusaki et al. were able to describe data of nonstoichiometry of $\mathrm{La}_{1-x} \mathrm{Sr}_{x} \mathrm{FeO}_{3-\delta}{ }^{8}$ and $\mathrm{La}_{1-x} \mathrm{Sr}_{x} \mathrm{CrO}_{3-\delta}$ from thermogravimetric measurements, using a model based on randomly distributed and noninteracting point defects. Applying the model to $\mathrm{La}_{1-x} \mathrm{Sr}_{x} \mathrm{CoO}_{3-\delta}$, Co-ions are charge disproportionated among oxidation states $\mathrm{Co}^{2+}$, $\mathrm{Co}^{3+}$, and $\mathrm{Co}^{4+}$. Using Kröger-Vink notation, ${ }^{10}$ this reaction can be represented as

$$
2 \mathrm{Co}_{\mathrm{Co}}^{x} \rightleftarrows \mathrm{Co}_{\mathrm{Co}_{\mathrm{o}}}^{\cdot}+\mathrm{Co}_{\mathrm{Co}}^{\prime}
$$

and is bounded by the requirement of charge neutrality. Oxygen incorporation may be described by

$$
\mathrm{O}_{2}+2 \mathrm{~V}_{\mathrm{o}}^{\ddot{*}}+4 \mathrm{Co}_{\mathrm{Co}_{\mathrm{o}}}^{x} \rightleftarrows 2 \mathrm{O}_{\mathrm{o}}^{x}+4 \mathrm{Co}_{\mathrm{Co}_{\mathrm{o}}}^{\cdot}
$$

in which reaction the formation of two regular lattice oxygen ions is charge compensated by the oxidation of four regular Co lattice ions. Since all point defects are assumed to be noninteracting and randomly distributed, the corresponding chemical potentials are of the following type ${ }^{2}$

$$
\mu_{\mathrm{k}}=\mu_{\mathrm{k}}^{0}+R T \ln ([k])
$$

where $\mu_{\mathrm{k}}$ is the chemical potential of the $k$ th structure element and $[k]$ its mole fraction. Substituting the appropriate chemical potentials into the equilibrium conditions for both reactions 4 and 5 , the following expressions are obtained

$$
\begin{gathered}
E_{\mathrm{i}}-T S_{\mathrm{i}}+R T \ln \left(\frac{\left[\mathrm{Co}_{\mathrm{Co}}^{\prime}\right]\left[\mathrm{Co}_{\mathrm{Co}}^{*}\right]}{\left[\mathrm{Co}_{\mathrm{Co}}^{x}\right]^{2}}\right)=0 \\
E_{\mathrm{ox}}-T S_{\mathrm{ox}}+2 R T \ln \left(\frac{\left[\mathrm{O}_{\mathrm{o}}^{x}\right]\left[\mathrm{Co}_{\mathrm{Co}}^{*}\right]^{2}}{\left[\mathrm{~V}_{\mathrm{o}}^{* *}\right]\left[\mathrm{Co}_{\mathrm{Co}}^{x}\right]^{2}}\right)=\mu_{\mathrm{O}_{2}}^{\text {gas }}
\end{gathered}
$$

where $E_{\mathrm{i}}$ and $S_{\mathrm{i}}$ are the respective energy and entropy associated with charge disproportionation according to reaction 4 , and $E_{\text {ox }}$ and $S_{\text {ox }}$ the respective energy and entropy associated with placing one oxygen molecule from vacuum into the oxide lattice by filling up two vacant lattice oxygen sites while creating four $\mathrm{Co}_{\mathrm{Co}_{0}}^{\prime}$ species according to reaction 5 . The above definitions for $S_{\mathrm{i}}$ and $S_{\mathrm{ox}}$ exclude the configurational entropy of point defects. If the thermodynamic quantities $E_{\mathrm{i}}, S_{\mathrm{i}}, E_{\mathrm{ox}}$, and $S_{\mathrm{ox}}$ are known, Eq. 7 and 8 can be used in conjunction with the condition for charge neutrality

$$
\left[\mathrm{Sr}_{\mathrm{La}_{\mathrm{a}}}\right]+\left[\mathrm{Co}_{\mathrm{C}_{0}}^{\prime}\right]=2\left[\mathrm{~V}_{\mathrm{O}}^{\bullet \cdot}\right]+\left[\mathrm{Co}_{\mathrm{Co}_{0}}^{\cdot}\right]
$$

and the structural conservation requirements

$$
\begin{gathered}
{\left[\mathrm{Co}_{\mathrm{Co}_{0}}^{x}\right]+\left[\mathrm{Co}_{\mathrm{Co}}^{\cdot}\right]+\left[\mathrm{Co}_{\mathrm{Co}_{0}}^{\prime}\right]=1} \\
{\left[\mathrm{O}_{\mathrm{O}}^{x}\right]+\left[\mathrm{V}_{\mathrm{O}}^{\cdot \bullet}\right]=3}
\end{gathered}
$$

to calculate the concentrations of all defect species as a function of $P_{\mathrm{O}_{2}}$ and temperature.

Expressions for the partial energy and entropy associated with oxygen incorporation have been derived by Mizusaki et al. ${ }^{11}$ The energy associated with oxygen incorporation is given by

$$
\epsilon_{\mathrm{O}_{2}}^{\text {oxide }}=E_{\mathrm{ox}}-\left(\frac{4 K_{\mathrm{i}}\left[\mathrm{Co}_{\mathrm{Co}}^{x}\right]+2\left[\mathrm{Co}_{\mathrm{C}_{0}}^{\prime}\right]}{4 K_{\mathrm{i}}\left[\mathrm{Co}_{\mathrm{C}_{0}}^{x}\right]+\left[\mathrm{Co}_{\mathrm{Co}}^{\prime}\right]+\left[\mathrm{Co}_{\mathrm{Co}}^{*}\right]}\right) \times 2 E_{\mathrm{i}}
$$

where the term between brackets is equal to $d\left[\mathrm{Co}_{\mathrm{Co}}^{\prime}\right] / d\left[\mathrm{~V}_{\mathrm{o}} \cdot\right.$ and varies between 0 and 2 . As a result, the value of $\epsilon_{\mathrm{O}_{2}}^{\text {oxide }}$ is equal to $E_{\mathrm{ox}}-2 E_{\mathrm{i}}$ in case the $\left[\mathrm{Co}_{\mathrm{Co}}^{\prime}\right] \gg\left[\mathrm{Co}_{\mathrm{Co}}^{-}\right]$and equal to $E_{\text {ox }}$ in case the $\left[\mathrm{Co}_{\mathrm{Co}_{0}}^{*}\right] \gg\left[\mathrm{Co}_{\mathrm{C}_{0}}^{\prime}\right]$. Similarly, the expression for the partial entropy associated with oxygen incorporation reads

$s_{\mathrm{O}_{2}}^{\text {oxide }}=S_{\mathrm{ox}}-\left(\frac{4 K_{\mathrm{i}}\left[\mathrm{Co}_{\mathrm{Co}_{0}}^{x}\right]+2\left[\mathrm{Co}_{\mathrm{Co}}^{\prime}\right]}{4 K_{\mathrm{i}}\left[\mathrm{Co}_{\mathrm{Co}}^{x}\right]+\left[\mathrm{Co}_{\mathrm{Co}}^{\prime}\right]+\left[\mathrm{Co}_{\mathrm{Co}}^{-}\right]}\right)$

$$
\times 2 S_{\mathrm{i}}+2 S^{\mathrm{cont}} \text {. }
$$

where $S^{\text {conf }}$ represents the configurational entropy. The latter can be calculated from

$$
\begin{aligned}
s^{\text {conf. }}=\left(\frac{4 K_{\mathrm{i}}\left[\mathrm{Co}_{\mathrm{Co}}^{x}\right]+2\left[\mathrm{Co}_{\mathrm{Co}}^{\prime}\right]}{4 K_{\mathrm{i}}\left[\mathrm{Co}_{\mathrm{Co}}^{x}\right]+\left[\mathrm{Co}_{\mathrm{Co}}^{\prime}\right]+\left[\mathrm{Co}_{\mathrm{Co}}^{\cdot}\right]}\right) \\
\times R \ln \left(\frac{\left[\mathrm{Co}_{\mathrm{Co}}^{\prime}\right]}{\left[\mathrm{Co}_{\mathrm{Co}}^{x}\right]}\right)-\left(\frac{4 K_{\mathrm{i}}\left[\mathrm{Co}_{\mathrm{Co}}^{x}\right]+2\left[\mathrm{Co}_{\mathrm{Co}}^{-}\right]}{4 K_{\mathrm{i}}\left[\mathrm{Co}_{\mathrm{Co}}^{x}\right]+\left[\mathrm{Co}_{\mathrm{Co}}^{\prime}\right]+\left[\mathrm{Co}_{\mathrm{Co}}^{*}\right]}\right) \\
\times R \ln \left(\frac{\left[\mathrm{Co}_{\mathrm{Co}}^{*}\right]}{\left[\mathrm{Co}_{\mathrm{Co}}^{x}\right]}\right)+R \ln \left(\frac{\left[\mathrm{V}_{\mathrm{o}}^{* *}\right]}{\left[\mathrm{O}_{\mathrm{O}}^{x}\right]}\right)
\end{aligned}
$$

$S^{\text {conf. }}$ thus consists of the configurational entropy of the oxygen vacancies in addition to a fractional part of the configurational entropies of both $\mathrm{Co}_{\mathrm{Co}}^{\prime}$ and $\mathrm{Co}_{\mathrm{Co}}^{\circ}$ species.

Nonstoichiometry models: Itinerant electron model.-In this model it is assumed that the conduction electrons, $e^{\prime}$, occupy electron states of a partially filled electron band. The oxidation reaction in this case becomes

$$
\mathrm{O}_{2}^{\text {gas }}+2 \mathrm{~V}_{\circ}^{*}+4 e^{\prime \prime} \rightleftarrows 2 \mathrm{O}_{\mathrm{o}}^{x}
$$

From Eq. 15, it is seen that pumping oxygen into the oxide lattice leads to adjustment of both the lattice oxygen vacancy and the conduction electron concentration. In the itinerant electron model it is again assumed that oxygen vacancies are noninteracting and distributed randomly among equivalent oxygen sites, which allows the use of chemical potentials of the type given by Eq. 6 for both oxygen vacancies and regular lattice oxygen ions. In principle, coulombic interactions between oxygen vacancies can give rise to an energy part of its chemical potential that increases with increasing oxygen vacancy concentration. ${ }^{2}$ Such a contribution is neglected here since it is not observed in the related structure $\mathrm{La}_{0.8} \mathrm{Sr}_{0.2} \mathrm{FeO}_{3-\delta}{ }^{8}$ In the latter oxide, the value of the electric conduction ${ }^{12}$ is smaller than that of $\mathrm{La}_{0.8} \mathrm{Sr}_{0.2} \mathrm{CoO}_{3-\delta}^{5}$ and, hence, one expects that screening of coulombic vacancy interactions would be even more effective in the cobaltite perovskite.

Next, an expression is derived relating $\mu_{\mathrm{e}}$, to the electron occupancy defined as $\left[e^{\prime}\right]=N_{\mathrm{e}^{\prime}} / N$, where $N_{\mathrm{e}^{\prime}}$ is the total number of conduction electrons in the partially filled electron band. The chemical potential of free electrons in such bands is equal to the Fermi energy, $\epsilon_{\mathrm{F}}$. Using the one-electron approximation, $\left[e^{\prime}\right]$ may be evaluated by integrating the Fermi-Dirac distribution function, $f(\epsilon)$, multiplied by the density of states, $g(\epsilon)$, over the total bandwidth

$$
\left[e^{\prime}\right] \int_{\epsilon=\epsilon_{\mathrm{b}}}^{\epsilon=\epsilon_{\mathrm{t}}} g(\epsilon) f(\epsilon) d \epsilon \approx \int_{\epsilon=\epsilon_{\mathrm{b}}}^{\epsilon=\epsilon_{\mathrm{F}}} g(\epsilon) d \epsilon
$$

where $\epsilon_{\mathrm{b}}$ and $\epsilon_{\mathrm{t}}$ are the energies at the bottom and the top of the band, respectively. Note that the approximation made in Eq. 16 is based on the assumption that all electron states below $\epsilon_{\mathrm{F}}$ are occupied while those above are unoccupied. In practice, electron states within a few $k_{\mathrm{B}} T$ of $\epsilon_{\mathrm{F}}$ are partially filled, but this effect can be neglected in case the bandwidth is large compared to $k_{\mathrm{B}} T$. The overall electron entropy thus has negligible influence on the electron chemical potential. Using the first-order Tailor expansion of Eq. $16, \mu_{\mathrm{e}^{\prime}}$ can be expressed in terms of $\left[e^{\prime}\right]$ and $g\left(\epsilon_{\mathrm{F}}\right)$

$$
\mu_{\mathrm{e}^{\prime}}\left(\left[e^{\prime}\right]\right)=\epsilon_{\mathrm{F}}\left(\left[e^{\prime}\right]=\left[e^{\prime}\right]^{0}\right)+\frac{\left(\left[e^{\prime}\right]-\left[e^{\prime}\right]^{0}\right)}{g\left(\epsilon_{\mathrm{F}}\right)}
$$

where $\left[e^{\prime}\right]^{0}$ is defined as the electron occupation number at zero vacancy concentration. When using Eq. 17 in combination with charge neutrality $\left(\left[e^{\prime}\right]-\left[e^{\prime}\right]^{0}=2 \delta\right)$ to calculate variations in $\mu_{\mathrm{e}^{\prime}}$ with increasing or decreasing vacancy concentration, it is implicitly assumed that the shape of the band is unchanged. The above applied formalism for relating changes in the concentration of ionized impurities to variations in the Fermi-level is referred to as the electron gas rigid band model. ${ }^{13}$

An expression for the equilibrium between the oxide and oxygen in the gas phase can be formulated, from com- 
bining Eq. 6 and 17 with the equilibrium condition for reaction 15 and the charge neutrality condition

$$
E_{\text {ox }}-T S_{\text {ox }}+2 R T \ln \left(\frac{\left[\mathrm{O}_{\mathrm{O}}^{x}\right] \exp \left(\frac{-4\left[\mathrm{~V}_{\mathrm{o}}^{* *}\right]}{R T g\left(\epsilon_{\mathrm{F}}\right)}\right)}{\left[\mathrm{V}_{\circ}^{* *}\right]}\right)=\mu_{\mathrm{O}_{2}}^{\text {gas }}
$$

where $E_{\mathrm{ox}}$ and $S_{\mathrm{ox}}$ are the respective energy and entropy associated with placing one oxygen molecule from vacuum into the oxide by filling up two vacant oxygen lattice sites while placing four electrons at the Fermi level. In these definitions, $E_{\text {ox }}$ excludes the change in Fermi level with changing electron occupancy and $S_{\text {ox }}$ excludes the configurational entropy of oxygen vacancies and regular lattice ions. If the thermodynamic quantities $E_{0 \mathrm{x}}$ and $S_{\mathrm{ox}}$ and the density of states at the Fermi-level $g\left(\epsilon_{\bar{F}}\right)$ are known, Eq. 18 in conjunction with Eq. 11 can be used to calculate the oxygen vacancy concentration as function of oxygen partial pressure and temperature.

Expressions for the partial energy and entropy of oxygen incorporation are much simpler than those for the charge disproportionation model due to the presence of only one type of electronic defect. The energy of oxygen incorporation follows from Eq. 2 and 18

$$
\epsilon_{\mathrm{O}_{2}}^{\text {oxide }}=E_{\mathrm{ox}}-\frac{8\left[\mathrm{~V}_{\mathrm{O}}^{* *}\right]}{g\left(\epsilon_{\mathrm{F}}\right)}
$$

It is recognized that in this model changes in $\epsilon_{\mathrm{O}_{2}}^{\text {oxide }}$ originate from the changes in the Fermi level. The entropy of oxygen incorporation can be obtained from Eq. 2 and 18

$$
s_{\mathrm{O}_{2}}^{\text {oxide }}=S_{\mathrm{ox}}+2 R \ln \left(\frac{\left[\mathrm{V}_{\mathrm{o}}^{* *}\right]}{\left[\mathrm{O}_{\mathrm{o}}^{x}\right]}\right)
$$

It is emphasized once more that in this model the electron entropy is negligible. One may further note from expressions 19 and 20 that in the itinerant electron model both $\epsilon_{\mathrm{O}_{2}}^{\text {oxide }}$ and $S_{\mathrm{O}_{2}}^{\text {oxide }}$ are independent of temperature.

\section{Experimental}

The measurements were performed with two electrochemical cells which were described in Part I of this paper. $^{7}$ In both cells, a cylindrically shaped disk of $\mathrm{La}_{0.8} \mathrm{Sr}_{0.2} \mathrm{CoO}_{3-\delta}(0.66 \mathrm{~g})$ was enclosed in an electrochemical cell. $\mathrm{ZY} 13\left(\mathrm{Zr}_{0.87} \mathrm{Y}_{0.13} \mathrm{O}_{1.935}\right)$ solid electrolytes were used to pump oxygen in or out of the cell, and to measure the $E M F$. As reference gas, air $\left(P_{\mathrm{O}_{2}}=0.209\right)$ was used in this study.

Two kind of measurements were performed. In the first kind, the open-cell $E M F$ was measured at five different temperatures, i.e., $775,825,875,925$, and $975^{\circ} \mathrm{C}$, for various values of the oxygen nonstoichiometry of the sample. The difference in $E M F$ measured between two consecutive temperatures, at constant stoichiometry, was used to determine the values of $\epsilon_{\mathrm{O}_{2}}^{\text {oxide }}$ and $s_{\mathrm{O}_{3}}^{\text {oxide }}$ at the halfway temperature. The final values of $\epsilon_{\mathrm{O}_{2}}^{\text {oxide }}$ and $s_{\mathrm{O}_{2}}^{\text {oxide }}$ were calculated as the arithmetic mean of those obtained from heating up and cooling down measurements. These temperature step measurements were performed for values of $\delta$ between 0.01 and 0.085 using cell 2 . Between successive temperature steps, the oxygen stoichiometry of the sample was adjusted by electrochemically pumping oxygen in or out of the cell.

In the second kind of experiments, potentiostatic steps typically $25 \mathrm{mV}$ were applied between 0 and $200 \mathrm{mV}$ at $700,800,900$, and $1000^{\circ} \mathrm{C}$ using cell 1 . Similar potentiostatic steps were applied with cell 2 at the temperatures 750,850 , and $950^{\circ} \mathrm{C}$. The change in oxygen nonstoichiometry $\Delta \delta$ associated with each step in oxygen partial pressure was calculated by numerical integration of the decay current according to Eq. 3 . The final value of $\Delta \delta$ was calculated as the arithmetic mean of the ones obtained from reduction and oxidation steps. The difference in all cases was below $5 \times 10^{-4}$. No correction was applied for the change in oxygen concentration of the gas inside the cell. The stoichiometry at $800^{\circ} \mathrm{C}$ in equilibrium with air, as reported by Mizusaki, ${ }^{14}$ was taken as the reference point. The relative positions of the resulting $\delta-P_{\mathrm{O}_{2}}$ lines were determined from $E M F-T$ measurements at constant oxygen stoichiometry. The measurements described above are henceforth referred to as voltage step measurements.

\section{Results and Discussion}

Temperature step measurements.-Figures 1 and 2 show

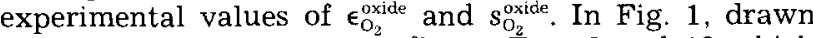
lines indicate least squares fits to Eq. 12 and 13 which were derived from the charge disproportionation model. In Fig. 2, drawn lines indicate best fits using Eq. 19 and 20 which were derived assuming itinerant electron behavior. Thermodynamic quantities obtained from fitting using the charge disproportionation model and the itinerant electron model are given in Table I and II, respectively. Within experimental error both $\epsilon_{\mathrm{O}_{2}}^{\text {oxide }}$ and $s_{\mathrm{O}_{2}}^{\text {oxide }}$ are independent of temperature. This observation would be in agreement with expressions 19 and 20 derived from the itinerant electron model. The experimental data do not allow an easy discrimination between both models, even though a slightly better fit is obtained within the itinerant electron model. Tai et $a l^{6}$ found that the Seebeck coefficient in $\mathrm{La}_{08} \mathrm{Sr}_{0,2} \mathrm{CoO}_{3-\delta}$ decreases from approximately $20 \mu \mathrm{V} / \mathrm{K}$ at room temperature to values less than $10 \mu \mathrm{V} / \mathrm{K}$ above $600^{\circ} \mathrm{C}$. The authors attributed this effect to the increase in $\mathrm{Co}_{\mathrm{C}}^{\circ}$ species with increasing temperature due to charge disproportionation of $\mathrm{Co}_{\mathrm{C}_{\mathrm{o}}}^{x}$ into $\mathrm{Co}_{\mathrm{Co}}^{*}$ and $\mathrm{Co}_{\mathrm{Co}}^{*}$. From fitting the experimental Seebeck data to an expression based on the configurational entropy of $\mathrm{Co}_{\mathrm{C}_{0}}^{*}$ and $\mathrm{Co}_{\mathrm{Co}}^{-}$species, they found $E_{\mathrm{i}}$ to be about $1.2 \mathrm{~kJ} / \mathrm{mol}$, which value may be compared with the much higher value of $34 \mathrm{~kJ} / \mathrm{mol}$ obtained from the present study. The latter value implies that, below about $400^{\circ} \mathrm{C}$, charge disproportionation does not take place, and an invariant Seebeck coefficient of
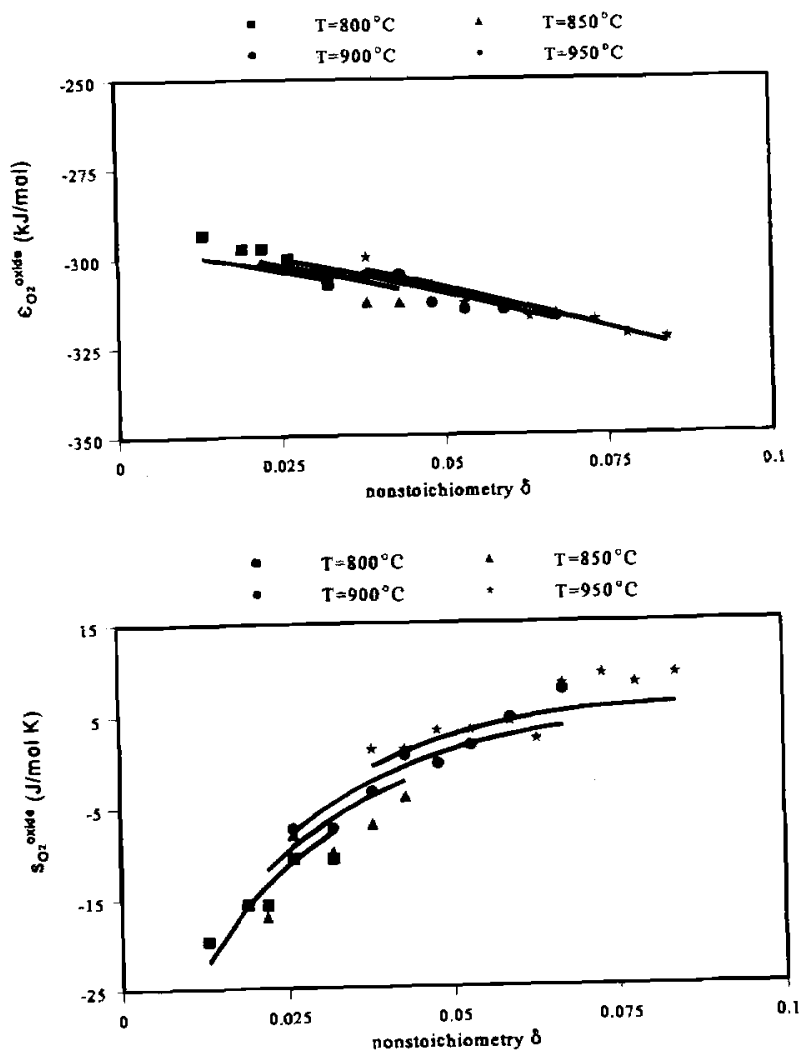

Fig. 1. Plot of (a, topl partial energy $\epsilon_{\mathrm{O}_{2}}^{\text {oxide }}$ and (b, bottom) partial entropy $s_{0}^{\text {oxide }}$ as a function of $\delta$. Drawn lines indicate best fits to Eq. 12 and 13, respectively, (charge disproportionation model). 

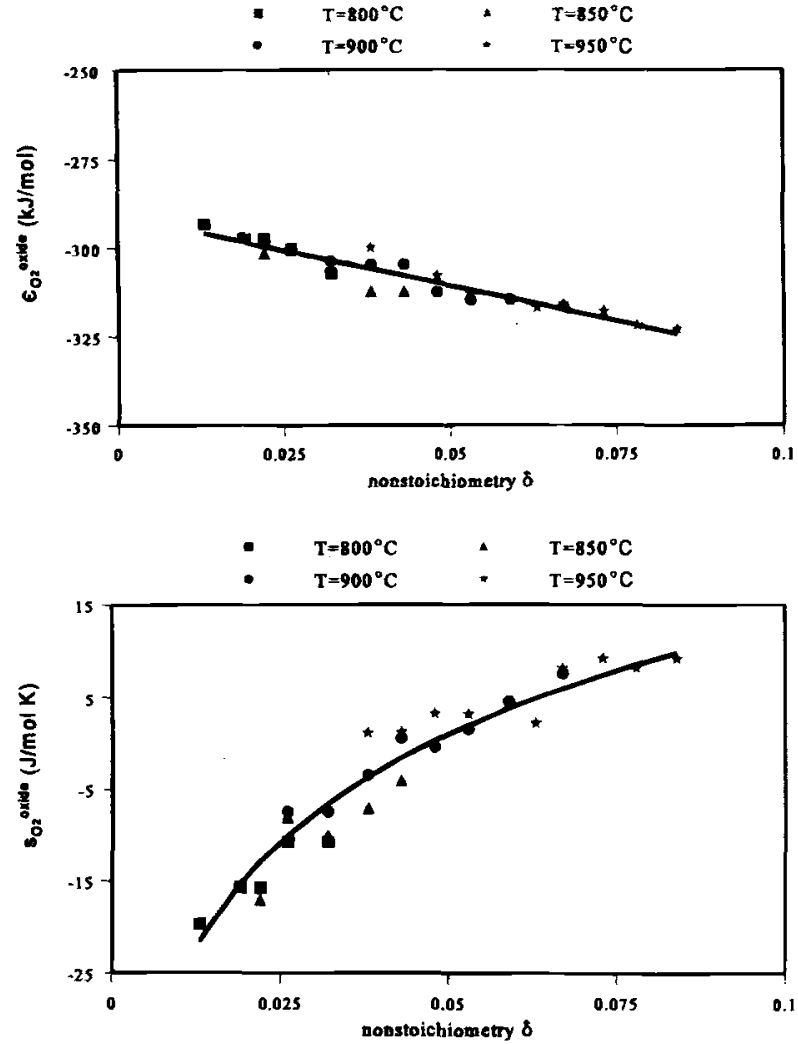

Fig. 2. Plot of ( $a$, top) partial energy $\epsilon_{O_{2}}^{\text {oxide }}$ and ( $b$, boltom) partial entropy $s_{0}^{\text {oxide }}$ as a function of $\delta$. Drawn lines indicate best fits to Eq. 19 and 20, ruspectively, (itinerant electron model).

$120 \mu \mathrm{V} / \mathrm{K}$ is anticipated. It thus seems that the charge disproportionation model is not valid for $\mathrm{La}_{0.8} \mathrm{Sr}_{0,2} \mathrm{CoO}_{3-\bar{\delta}}$. For the itinerant electron model no simple expression can be derived which relates the Seebeck coefficient to temperature and Fermi level. Such an expression depends on the detailed structure of the band of which little knowledge is available. The presence of a partially filled wide electron band however predicts the Seebeck coefficient to be of the same order of magnitude as measured for common metals. The low Seebeck coefficients experimentally observed for $\mathrm{La}_{0.8} \mathrm{Sr}_{0.2} \mathrm{CoO}_{3-\delta}$ are in accordance with this prediction.

The good agreement noted between experimental data of $s_{O_{2}}^{\text {oxide }}$ and theoretical values calculated from the itinerant electron model supports the assumption of negligibly small configurational entropy of electrons and that of randomly distributed oxygen vacancies. The latter assumption implies that all lattice oxygen vacancies are equivalent, which is consistent with experimental data of oxygen permeation through phases $\mathrm{La}_{1-x} \mathrm{Sr}_{x} \mathrm{CoO}_{3-\delta}$. Van Doorn et al. ${ }^{15}$ showed that the oxygen permeation is proportional

Table I. Parameters obtained from fitting experimental data of

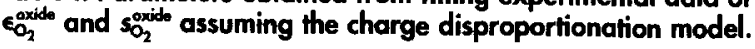

$\begin{array}{lc}E_{\mathrm{ox}}(\mathrm{kJ} / \mathrm{mol}) & -269.2 \\ S_{\mathrm{ox}}(\mathrm{J} / \mathrm{mol} \mathrm{K}) & 58.6 \\ E_{\mathrm{i}}(\mathrm{kJ} / \mathrm{mol}) & 34.2 \\ S_{\mathrm{i}}(\mathrm{J} / \mathrm{mol} \mathrm{K}) & 0.458\end{array}$

Table H. Porameters oblained from fitting experimental data of $\epsilon_{\mathrm{O}_{2}}^{\text {oxide }}$ and $\mathrm{s}_{2}^{\text {oxide }}$ assuming the itinerant electron model.

$\begin{array}{lc}E_{\mathrm{ox}}(\mathrm{kJ} / \mathrm{mol}) & -290.3 \\ S_{\mathrm{ox}}(\mathrm{J} / \mathrm{mol} \mathrm{K}) & 68.7 \\ g\left(\mathbf{\epsilon}_{\mathrm{F}}\right)\left((\mathrm{kJ} / \mathrm{mol})^{-1}\right) & 0.0198 \\ g\left(\mathbf{\epsilon}_{\mathrm{F}}\right)\left((\mathrm{eV})^{-1}\right) & 1.9\end{array}$

to the oxygen nonstoichiometry, from which it can be concluded that all oxygen vacancies are involved in the oxygen transport.

A consequence of the itinerant electron model is the increase in Fermi level with increasing electron occupancy, at a rate determined by the value of $g\left(\epsilon_{F}\right)$. From the experimental decrease in $\epsilon_{\mathrm{O}_{2}}^{\text {oxide }}$ with increasing $\delta$ the value of $g\left(\epsilon_{\mathrm{F}}\right)$ in $\mathrm{La}_{0.8} \mathrm{Sr}_{0.2} \mathrm{CoO}_{3-8}$ is estimated at $1.9(\mathrm{eV})^{-1}$. This value is of similar order of magnitude as the $1.0(\mathrm{eV})^{-1}$ and $1.3(\mathrm{eV})^{-1}$ obtained from the shift in the $\mathrm{O} 2 \mathrm{p}$ band toward the Fermi level with increasing $\mathrm{Sr}$ content as measured using XPS., ${ }^{4,16}$

McKinnon and Selwyn ${ }^{17}$ criticized the use of the socalled electron gas rigid band model in which the Fermi level raises when the band is filled due to ionization of added impurities. With reference to the screened impurity rigid band model developed by Friedel ${ }^{18}$ these authors assume that as a result of the presence of the ionized impurities the entire electron band shifts due to the perturbation constituted by the screened impurity potential. Since the latter shift is exactly opposite to that of the Fermi level relative to the bandedges, the Fermi level on an absolute energy scale remains unaltered. This model can, however, not explain the good correlation found between measured chemical potential variations for alkali metal intercalated transition metal dichalcogenides and corresponding density of states calculations ${ }^{19}$ and data from $x$-ray absorption measurements. ${ }^{20} \mathrm{~A}$ constant Fermi level neither might explain the decrease in $\epsilon_{\mathrm{O}_{2}}$ with increasing $\delta$ observed in this study. For $\mathrm{La}_{0.8} \mathrm{Sr}_{0.2} \mathrm{CoO}_{3-\delta}$, one might consider that screening of oxygen vacancies by the conduction electrons only partly balances the upwards shift in Fermi level with increasing electron occupancy. This would also explain as to why the value of $g\left(\epsilon_{F}\right)$ determined from this study is somewhat larger than those obtained with XPS.

Voltage step measurements.-Typical values for the leakage current determined at $950^{\circ} \mathrm{C}$ are 5 to $20 \mu \mathrm{A}$ for cell 1 and 15 to $30 \mu \mathrm{A}$ for cell 2 . At temperatures below $850^{\circ} \mathrm{C}$ the leakage currents were too small to be measured. Reproducible values of the leakage current were found in different experiments. The leakage is attributed to the mixed conducting properties of the zirconia electrolyte(s).

In Fig. 3, $\log (8)$ is plotted against $\log \left(P_{\mathrm{O}_{2}}\right)$ at several temperatures. The results obtained with both cells were found to be in good agreement with the data obtained by Mizusaki et al. ${ }^{14}$ from thermogravimetry. The log $(\delta)-$ $\log \left(P_{\mathrm{O}_{2}}\right)$ curves are almost straight lines with a slope, $\gamma$, equal to $-0.23 \pm 0.02$. Substituting Eq. A-1 into Eq. 18, partial differentiation of $\log \left(P_{\mathrm{O}_{2}}\right)$ with respect to $\log (\delta)$ shows that the itinerant electron model predicts $\gamma$ to be a function of $\delta$ and $g\left(\epsilon_{\mathrm{F}}\right)$

$$
\gamma=-\left(2\left(\frac{3}{3-\delta}\right)+\frac{8 \delta}{k_{\mathrm{B}} T g\left(\epsilon_{\mathrm{F}}\right)}\right)^{-1}
$$

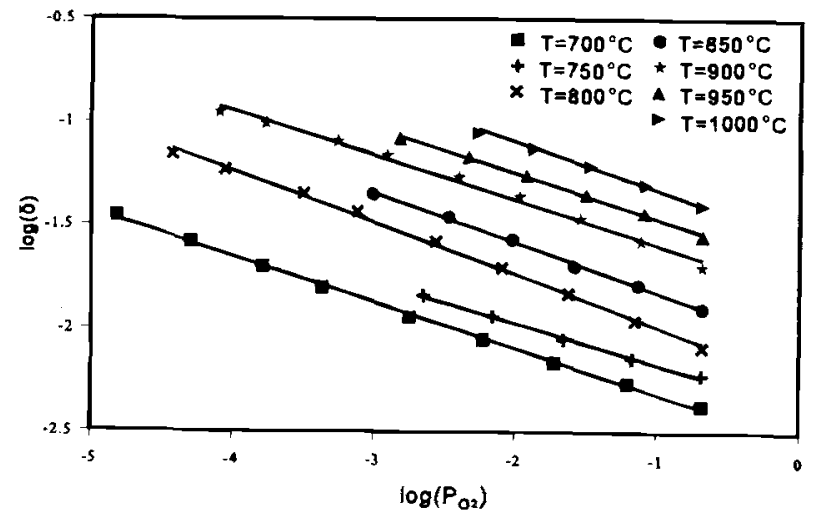

Fig. 3. Plot of $\log (8)$ as a function of $\log \left(P_{O_{2}}\right)$. Data was determined from voltage step measurements. 
Substituting the value for $g\left(\epsilon_{\mathrm{F}}\right)$, taking an average value of $\delta$ equal to 0.05 , and $T$ in the range $973 \mathrm{~K}<T<1223 \mathrm{~K}$ yields $\gamma=0.24 \pm 0.02$, which fairly agrees with the overall value obtained from the experimental results.

Clearly, there is no plateau corresponding to a constant vacancy concentration as observed at $\delta=\left[\mathrm{Sr}_{\mathrm{La}}^{\prime}\right] / 2$ in the related compounds $\mathrm{La}_{1-x} \mathrm{Sr}_{x} \mathrm{FeO}_{3-\delta}{ }^{8}$ and $\mathrm{La}_{1-x} \mathrm{Sr}_{x} \mathrm{CrO}_{3-\delta}{ }^{9}$ In the charge disproportionation model, the appearance of such a plateau corresponds with the situation in which the Sr dopant concentration is charge balanced by the vacancy concentration, while the concentrations of transition metal ions with valence $2+$ or $4+$ are negligibly small. The width of the plateau region decreases with the extent of charge disproportionation among the transition metal atoms. No plateau is expected from the itinerant electron model.

In Fig. 4 , the data of Fig. 3 are shown in a $\delta v s . \mu_{0_{3}}^{\text {oxide }}$ plot. Theoretical lines were calculated from Eq. 18 using the thermodynamic quantities listed in Table II. The good agreement noted between experimental and theoretical values shows that the temperature step measurements and the voltage step measurements are consistent. All data points fall nearly onto a single curve. That is, for each value of $\delta, \mu_{0}^{\text {oxide }}$ is nearly temperature independent. Since in equilibrium $\mu_{\mathrm{O}_{2}}^{\text {oxide }}$ is equal to the gas-phase oxygen chemical potential, the observed temperature dependence of $P_{\mathrm{O}_{2}}$ at constant $\delta$ must result from balancing the change of $\mu_{\mathrm{O}_{2}}^{\text {.rgas }}$ with temperature (see Appendix A). Since Fig. 1 shows that $\epsilon_{\mathrm{O}_{2}}^{\text {oxide }}$ is nearly temperature independent, a temperature independent $\mu_{\mathrm{O}_{2}}^{\text {oxide }}$ is expected when $T \times s_{\mathrm{O}_{2}}^{\text {oxide }}$ is small. From Fig. 2, it may be evaluated that $T \times s_{\mathrm{O}_{2}}^{\text {axide }}$ is indeed small compared with changes in $\mu_{\mathrm{O}_{2}}^{\text {sxide }}$ with $\delta$.

\section{Conclusions}

The logarithm of the oxygen nonstoichiometry in $\mathrm{La}_{0.8} \mathrm{Sr}_{0.2} \mathrm{CoO}_{3-\delta}$ is linearly related to the logarithm of the oxygen partial pressure with a slope given by $-0.23 \pm$ 0.02 . Contrary to related compounds $\mathrm{La}_{0.8} \mathrm{Sr}_{0.2} \mathrm{FeO}_{3-\delta}$ and $\mathrm{La}_{08} \mathrm{Sr}_{02} \mathrm{CrO}_{3-\delta}$, no plateau is observed in the nonstoichiometry plot $v s$. oxygen partial pressure at $\delta=0.1$. Measured data of the energy and entropy associated with incorporation of oxygen into $\mathrm{La}_{0.8} \mathrm{Sr}_{0.2} \mathrm{CoO}_{3-\delta}$ can be fitted reasonably well using the defect model based on the charge disproportionation of $2 \mathrm{Co}_{\mathrm{Co}}^{x}$ into $\mathrm{Co}_{\mathrm{Co}_{0}}^{\prime}$ and $\mathrm{Co}_{\mathrm{Co}}^{*}$. The resulting thermodynamic parameters, however, do not agree with those obtained from applying the same model for interpreting experimental data from Seebeck measurements. Data of both partial energy and entropy can also be interpreted in terms of a model in which it is assumed that electrons created during vacancy formation sequentially fill electron states in a broad electron band. This model further implies that changes in the value of $\epsilon_{\mathrm{O}_{2}}$ are directly related to changes in the value of the Fermi level, while variations in $s_{\mathrm{O}_{2}}$ with changing $\delta$ are due to the configura-

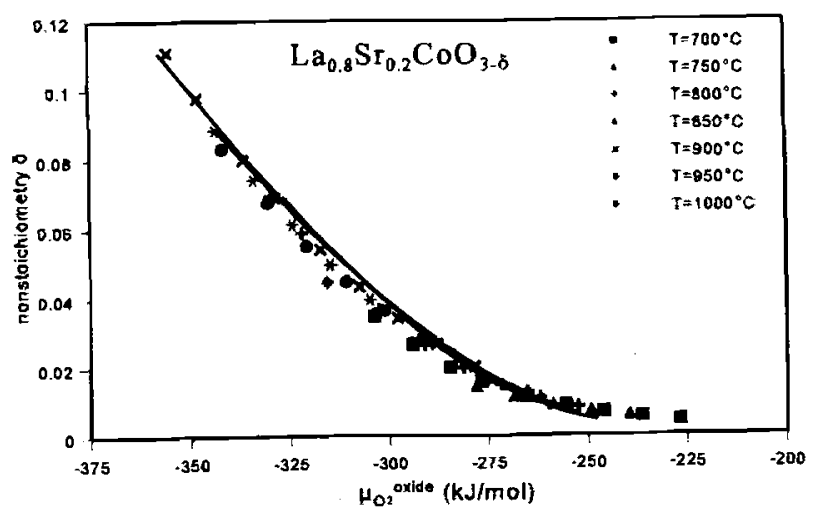

Fig. 4. Plot of $\delta$ as a function of $\log \left(P_{O_{2}}\right)$. The experimental values were determined from voltage step measurements. Theoretical lines are calculated from Eq. 18 using the values presented in Table II.

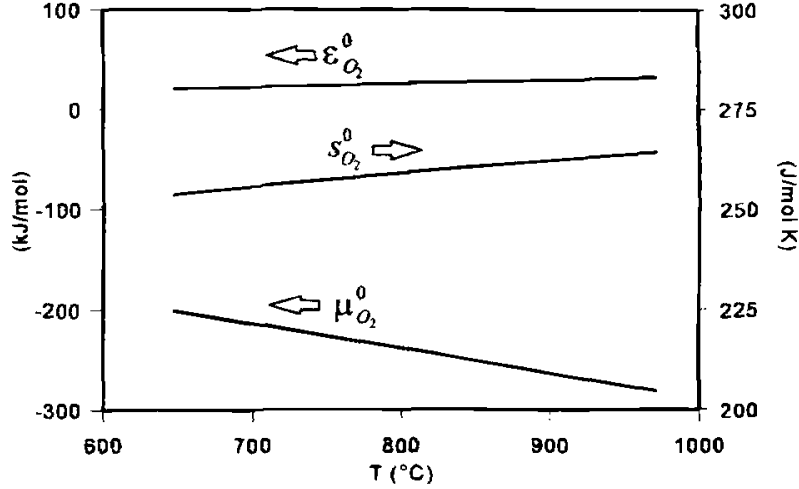

Fig. 5. Plot of $\mu_{O_{2}}^{\mathrm{O} g a s}$ and its energy $\epsilon_{O_{2}}^{0 \text { gas }}$ and entropy part $s_{\mathrm{O}_{2}}^{\mathrm{O} \text { gas }}$ as a function of temperature. Data was evaluated from Eq. A-1.

tional entropy of the oxygen vacancies. Based on this model, an expression has been derived relating oxygen nonstoichiometry to temperature and oxygen partial pressure, which clearly deviates from a mass-action type of law.

Manuscript received July 16, 1996.

The University of Twente assisted in meeting the publication costs of this article.

\section{APPENDIX}

\section{Gas-Phase Oxygen Chemical Potential}

The chemical potential of oxygen in the gas phase is given by ${ }^{21}$

$$
\begin{gathered}
\mu_{\mathrm{O}_{2}}^{\mathrm{gas}}=\mu_{\mathrm{O}_{2}}^{0, \text { gas }}+R T \ln \left(P_{\mathrm{O}_{2}}\right) \\
\mu_{\mathrm{O}_{2}}^{0, \text { gas }}=R T\left(n_{1}+n_{2} \frac{1}{T}+n_{3} \ln (T)+n_{4} \ln \left(1-e^{\frac{-n_{5}}{T}}\right)\right)
\end{gathered}
$$

where $T$ is the temperature in kelvin, in atm and

$$
\begin{aligned}
& n_{1}=-1.225 \\
& n_{2}=-1.045 \cdot 10^{3} \mathrm{~K} \\
& n_{3}=-3.500 \\
& n_{4}=1.013 \\
& n_{5}=2.242 \cdot 10^{3} \mathrm{~K}
\end{aligned}
$$

In Fig. 5 , $\mu_{O_{2}}^{\text {o.gas }}$ and its energy $\epsilon_{O_{2}}^{0 . g a s}$ and entropy part $s_{O_{2}^{0}}^{\text {ogas }}$ are plotted as a function of temperature.

\section{REFERENCES}

1. F A. Kröger, The Chemistry of Imperfect Crystals, Vol. 2, 2nd ed., Chap. 9 (1964).

2. M. H. R. Lankhorst, H. J. M. Bouwmeester, and H. Verweij, J. Amer. Ceram. Soc., Submitted.

3. J. Mizusaki, Solid State lonics, 52, 79 (1992).

4. D. D. Sarma and A. J. Chainani, J. Solid State Chem., 111, 208, (1994).

5. J. Mizusaki, J. Tabuchi T. Matsuura, S. Yamauchi, and K. Fueki, This Journal, 136, 2082 (1989).

6. L. W. Tai, M. M. Nasrallah, H. U. Anderson, D. M. Sparlin, and S. R. Sehlin, Solid State Ionics, 76, 273 (1995).

7. M. H. R. Lankhorst and H. J. M. Bouwmeester, This Journal, 144, 1261 (1997).

8. J. Mizusaki, M. Yoshihiro, S. Yamauchi, and K. Fueki, J Solid State Chem., 67, 1 (1987).

9. J. Mizusaki, S. Yamauchi, K. Fueki, and A. Ishíkawa, Solid State Ionics, 12, 119 (1984)

10. F. A. Kröger and H. J. Vink, in Solid State Physics, Vol. 3, F. Seitz and D. Turnball, Editors, p. 307, (1956).

11. J. Mizusaki, M. Yoshihiro, S. Yamauchi, and K. Fueki, J. Solid State Chem., 67, 1 (1987).

12. J. Mizusaki, T. Sasamoto, W. R. Cannon, and H. K. Bowen, J. Amer. Ceram. Soc., 66, 247 (1983).

13. D. J. Sellmyer, in Solid State Physics, Vol. 33, H. 
Ehrenreich, F. Seitz, and D. Turnball, Editors, p. 83 (1978).

14. J. Mizusaki, Y. Mima, S. Yamauchi, K. Fueki, and H. Tagawa, J. Solid. State Chem., 80, 102, (1989).

15. R. H. E, van Doorn, H. Kruidhof, H. J. M. Bouwmeester, and A. J. Burggraaf, This Journal, Submitted.

16. J. P. Kemp, D. J. Beal, and P. A. Cox, J. Solid State Chem., 86, 50 (1990).

17. W. R. McKinnon and L. S. Selwyn, Phys. Rev. B, 35, 7275 (1987)
18. J. Friedel, Adv. Phys., 3, 446, (1954)

19. J. Rouxel, in Mater. Res. Symp. Proc., 135, G. Nazri, R. F. Huggins, and D. F. Shriver, Editors, p. 431, MRS (1989).

20. J. R. Dahn, J. N. Reimers, T. Tiedje, Y. Gao, A. K. Sleigh, W. R. McKinnon, and S. Cramm, Phys, Rev. Lett., 68, 835 (1992).

21. IUPAC, Commission on Thermodynamics; Oxygen, International Thermodynamic Tables of the Fluid State, Vol. 9, Blackwell Scientific Publications, Oxford (1987).

\title{
Determination of Chemical Diffusion Coefficients in Metal Hydride Particles with a Microelectrode Technique
}

\author{
Tatsuo Nishina, Hironori Ura, and Isamu Uchida* \\ Department of Molecular Chemistry and Engineering, Faculty of Engineering, Tohoku University, \\ Aramaki-Aoba, Aoba-Ku, Sendai 980-77, Japan
}

\begin{abstract}
Microelectrochemical studies for hydrogen storage materials have been carried out by using a microelectrode technique. A carbon fiber filament was contacted with single particles of $\mathrm{LaNi}_{4.5} \mathrm{Al}_{0.5}, \mathrm{LmNi}_{4.0} \mathrm{Cr}_{0.4} \mathrm{Mn}_{0.3} \mathrm{Al}_{0.3}, \mathrm{ZrNi}_{1.4}$, $\mathrm{ZrMn}_{0.6} \mathrm{Co}_{0.1} \mathrm{~V}_{0.2} \mathrm{Ni}_{1.2}$, and $\mathrm{ZrMn}_{0.4} \mathrm{Cr}_{0.4} \mathrm{Ni}_{1.2}$ in $1 \mathrm{M} \mathrm{KOH}$ solutions by using a micromanipulator, where Lm indicates the lanthanum-rich rare-earth metal. In this way, cyclic voltammetry and potential step experiments, together with the in situ x-ray diffraction experiments, were conducted and the apparent hydrogen diffusion coefficients in solid phases were determined. The current responses recorded as a function of time were analyzed with a spherical diffusion model and the results are reported herein.
\end{abstract}

\section{Introduction}

A microelectrode technique targeting a single particle of metal hydrides was applied to determine the chemical diffusion coefficient of hydrogen inside the solid phase. This technique, consisting of micromanipulation of a fine carbon filament to make an electric contact with a separated single particle in electrolytes, has proven very useful to study battery active materials with a powdered form, ${ }^{1}$ because it allows determination of the straightforward current/potential behavior of the sample particle itself without any dilution due to a binder and a conductive assistant.

$\mathrm{LaNi}_{5}$ is a typical hydrogen storage alloy ${ }^{2-4}$ and there are extensive studies on charge/discharge characteristics as the negative battery component..$^{5-7}$ The hydrogen diffusion coefficient in the alloys is an important parameter to understand the kinetic behavior of the cell component, and it has been measured by nuclear magnetic resonance ${ }^{B}$ and quasi-elastic neutron scattering methods. ${ }^{9}$ As to determination of a chemical diffusion coefficient, a current pulse technique was applied to thin amorphous films of Ni-Zr alloys prepared by melt-spinning and sputtering methods, ${ }^{10,11}$ a potential step method to a thin film of $\mathrm{LaNi}_{2}$ Laves phase prepared by sputtering, ${ }^{12}$ and the disk-type electrode of $\mathrm{AB}_{5}$-type $\mathrm{MmNi}_{4.2} \mathrm{Al}_{0.5} \mathrm{M}_{0.3}(\mathrm{Mm}=$ misch metal; $\mathrm{M}=\mathrm{Cr}, \mathrm{Mn}, \mathrm{Fe}, \mathrm{Co}, \mathrm{Ni}$ ) alloys. ${ }^{13}$ However, since most of the battery active materials are available in powdered forms, it is desirable to characterize their kinetic behavior in asreceived forms. Considering that a small particle can be contacted with a fine tip electrode by means of micromanipulation, ${ }^{1,14}$ we developed a new technique for characterization of the solid-phase electrochemistry of the redox particle and measured the chemical diffusion coefficients of hydrogen inside the $\mathrm{LaNi}_{5}$ and Pd particles by the potential step method in alkaline solutions. ${ }^{1}$

In the present work, we have extended our technique to determine the apparent hydrogen diffusion coefficients in the $\mathrm{AB}_{5}$-type alloys $\left(\mathrm{LaNi}_{4.5} \mathrm{Al}_{0.5}\right.$ and $\left.\mathrm{LmNi}_{4.0} \mathrm{Co}_{0.4} \mathrm{Mn}_{0.3} \mathrm{Al}_{0.3}\right)$

* Electrochemical Society Active Member. and the C15-type Laves phase alloys $\left(\mathrm{ZrNi}_{1.4}, \mathrm{ZrMn}_{0.6}\right.$ $\mathrm{Co}_{0.1} \mathrm{~V}_{0.2} \mathrm{Ni}_{1.2}$, and $\mathrm{ZrMn}_{0.4} \mathrm{Cr}_{0.4} \mathrm{Ni}_{1.2}$ ) particle electrodes in alkaline solutions, where Lm indicates the lanthanumrich rare-earth metal.

\section{Experimental}

Details of the experimental technique were reported in our previous paper. ${ }^{1}$ In this experiment, a carbon fiber (10 $\mu \mathrm{m}$ diam) microelectrode was employed as a current collector. The carbon fiber was coated with a thin film of Teflon to minimize the background current, then it was mounted into glass tubing and was held with an X-Y-Z micropositioner (Oyama, OYM-130). The tip of the carbon fiber was contacted with the particle by handling the positioner under a stereomicroscope (Nikon SMZ-U) with an enlargement of about 300 times. The particle dimension was determined by an optical image obtained under a micrometer eyepiece.

The particle size of the $\mathrm{AB}_{5}$-type alloys $\left(\mathrm{LaNi}_{45} \mathrm{Al}_{0.5}\right.$ and $\left.\mathrm{LmNi}_{4.0} \mathrm{Co}_{0.4} \mathrm{Mn}_{0.3} \mathrm{Al}_{0.3}\right)$ and the C15-type Laves phase alloys $\left(\mathrm{ZrNi}_{1.4}, \mathrm{ZrMn}_{0.6} \mathrm{Co}_{0.1} \mathrm{~V}_{0.2} \mathrm{Ni}_{1.2}\right.$, and $\left.\mathrm{ZrMn}_{0.4} \mathrm{Cr}_{0.4} \mathrm{Ni}_{1.2}\right)$ were adjusted to 200 to $100 \mu \mathrm{m}$ by passing through sieves. These particles were spread on a disk of glass frit soaked with a $1 M \mathrm{KOH}$ solution. Pt wire counterelectrode and the $\mathrm{Hg} / \mathrm{HgO}(1 M \mathrm{KOH})$ reference electrode were used. All experiments were carried out at room temperature.

All electrochemical measurements were carried out with a potentiostat (Hokuto Denko, HAB-501) coupled with an $\mathrm{X}-\mathrm{Y}$ recorder (Graphtec, WX1000). In potential step experiments, a pulse generator (Tohu Technical Research, FG-02) was used together with a digital voltage unit (Keithley, 2001) to record current responses. In the in situ XRD experiment, the conventional sheet electrodes of the $\mathrm{AB}_{5}$ and the $\mathrm{C} 15$ Laves phase alloys were used. The sheet electrodes were made by mixing the powder of the hydrogen storage alloys with polytetrafluoroethyl (PTFE) binder [3 weight percent (w/o)] and carbon ( $1 \mathrm{w} / \mathrm{o})$ as a conductor and then pressing it to the Ni-expanded metal at $3000 \mathrm{~kg} / \mathrm{cm}^{2}$. The in situ $\mathrm{x}$-ray diffraction (XRD) measurements were carried out using Shimadzu XD-610 and 